\title{
Assessing the Activity Concentration of Agricultural Products and the Public Ingestion Dose as Result of a Nuclear Accident
}

\author{
Dong-Kwon Keum*, Hyojoon Jeong, In Jun, Kwang-Muk Lim, Yong-Ho Choi \\ Nuclear Environmental Safety Research Division, Korea Atomic Energy Research Institute, Daejeon, Korea
}

\section{Original Research}

Received March 28, 2018

Revision May 29, 2018

Accepted June 12, 2018

Corresponding author:

Dong-Kwon Keum

Korea Atomic Energy Research Institute, 989 Daedeokdae-ro, Yuseong-gu,

Daejeon 34057, Korea

Tel: $+82-42-868-2058$

Fax: +82-42-868-8606

E-mail:dkkeum@kaeri.re.kr

This is an Open-Access article distributed under the terms of the Creative Commons Attribution NonCommercial License (http://creativecommons.org/ licenses/by-nc/4.0) which permits unrestricted noncommercial use, distribution, and reproduction in any medium, provided the original work is properly cited.

Copyright $\odot 2018$ The Korean Association for Radiation Protection



Background: A model to assess the activity concentration of agricultural products and the public ingestion dose as result of a nuclear accident is necessarily required to manage the contaminated agricultural systems by the accident, or to estimate the effects of chronic exposure due to food ingestion at a Level 3 PSA.

Materials and Methods: A dynamic compartment model, which is composed of three submodules, namely, an agricultural plant contamination assessment model, an animal product contamination assessment model, and an ingestion dose assessment model has been developed based on Korean farming characteristics such as the growth characteristics of rice and stockbreeding.

Results and Discussion: The application study showed that the present model can predict well the characteristics of the activity concentration for agricultural products and ingestion dose depending on the deposition date.

Conclusion: The present model is very useful to predict the radioactivity concentration of agricultural foodstuffs and public ingestion dose as consequence of a nuclear accident. Consequently, it is expected to be used effectively as a module for the ingestion dose calculation of the Korean agricultural contamination management system as well as the Level 3 PSA code, which is currently being developed.

Keywords: Nuclear accident, Ingestion dose, Level 3 PSA, Agricultural products, Activity concentration

\section{Introduction}

Radionuclides released into the environment as the result of a nuclear accident reach the inside of the human body through the ingestion of foodstuffs, which are contaminated with radionuclides by way of various pathways. The ingestion dose for the public due to the consumption of food contaminated with radionuclides is very useful information to manage the contaminated agricultural system, to determine the public protective measures after a nuclear accident, or to establish guidelines for the nuclear emergency in the preparedness stage. To evaluate the ingestion dose, a suitable assessment model and the relevant input parameters are necessarily required.

Since the Chernobyl nuclear accident in 1986, a variety of dynamic models to assess the ingestion dose following a nuclear accident have been developed in many coun- 
tries [1-6]. Among them, the FARMLAND code [5] was recently used by the United Nations Scientific Committee on Atomic Radiation Effect (UNSCEAR) to evaluate the effects of the Fukushima accident [7], and the ECOSY87 code [2] was used to predict the radiation dose of Koreans by the Fukushima accident [8]. The COMIDA code [3] is used as an ingestion dose assessment model of the MACSS for a Level3 PSA [9]. These models have been derived mostly based on agricultural characteristics of dry farmland, which is normal in the western countries. However, the agricultural practice of rice, which is a staple crop in the Asian region, is somewhat different from that of dry farmland. During the growth period of rice, there is normally the flooded surface water on the paddy field due to the supply of irrigation water [10]. In addition, rice straw after harvest is used as one of the main feedstuffs of cows. Thus, an ingestion dose model is necessary to be developed based on its own agricultural situations of each country for a more practical evaluation.

The purpose of the present study aims at presenting the model to assess the ingestion dose as the result of a nuclear accident, considering the Korean farming characteristics, such as the growth characteristics of rice and stockbreeding.

\section{Materials and Methods}

The present model consists of three parts: an agricultural plant contamination assessment model, an animal product contamination assessment model, and an ingestion dose assessment model.

Target foodstuffs and feedstuffs consumed should be first defined in order to develop an ingestion dose assessment model. The foodstuffs and feedstuffs vary greatly by each country. In general, a model does not consider all kinds of foodstuffs and feedstuffs because the relevant input parameters such as growth characteristics of agricultural plants and intake of individual food are not fully known. In the present model, eight foodstuffs of rice, vegetables, fruit, milk, beef, egg, chicken, and pork, which are currently being used for the purpose of domestic regulations, were considered. Rice was selected as a representative food of cereals since it is a major staple crop in Korea. Chinese cabbage, the vegetables which is consumed very much in Korea, was selected as a representative food of vegetables, although other vegetables such as radish, spinach, and leeks are also partly consumed. However, it should be noted that classifying agricultural plants into more specific groups in the model is not difficult provided that the growth characteristics of the individual plant are known.

Milk, beef, chicken, eggs, and pork were selected as main animal products. Pasture, rice straw, and corn were also selected as agricultural plants to be considered in the model because they are mainly being used as the fodder for raising livestock in Korea.

Details for the present model are here skipped owing to a limited space, and are described well elsewhere [11]. The summary of the model is given below.

\section{Agricultural plant contamination assessment model}

Figure 1 shows the transport pathway of radionuclide in agricultural plants system. The plants are modeled differently according to the type of crop. Rice and corn, of which a stem is used as feedstuffs of a livestock, is separated with the body (stem) and grain to evaluate the respective activity concentration of stem and grain, while vegetables and pasture, of which the whole part are edible, are divided into the surface and inner part of the plant. Therefore, when deposition occurs during the growing season of the crop, radionuclides are assumed to be deposited on the plant body for rice and corn, and on the plant surface for vegetables and pasture.

The transfer characteristics of radionuclides in paddy fields are somewhat different from that in dry-fields owing to the presence of the flooded irrigation water on the paddy field during most of the growing period. To model this characteristic, a surface water compartment, which corresponds to the surface soil compartment of dry fields, is introduced for a paddy field. In addition, the shoot base absorption from the surface water, which was indirectly identified from the rice experiments [10], is considered as an additional transfer pathway of radionuclides to rice.

On the other hand, when surface water contaminated with radionuclides is used for irrigation, the contaminated irrigation water is an additional source for the contamination of plants. In the present model, the effect of contaminated irrigation water is considered for rice and vegetables because the surface water such as river and lake is normally used for irrigation for the crops, whereas the effect is not considered for fruit under the assumption that groundwater of no contamination is used for irrigation. Pastures are assumed to be naturally wild and thus that there is no artificial plowing and irrigation for raising pasture. Since fruit trees are perennial, there is no plowing. No plowing leads to no soil mixing.

The soil is divided into four parts of surface soil (surface 


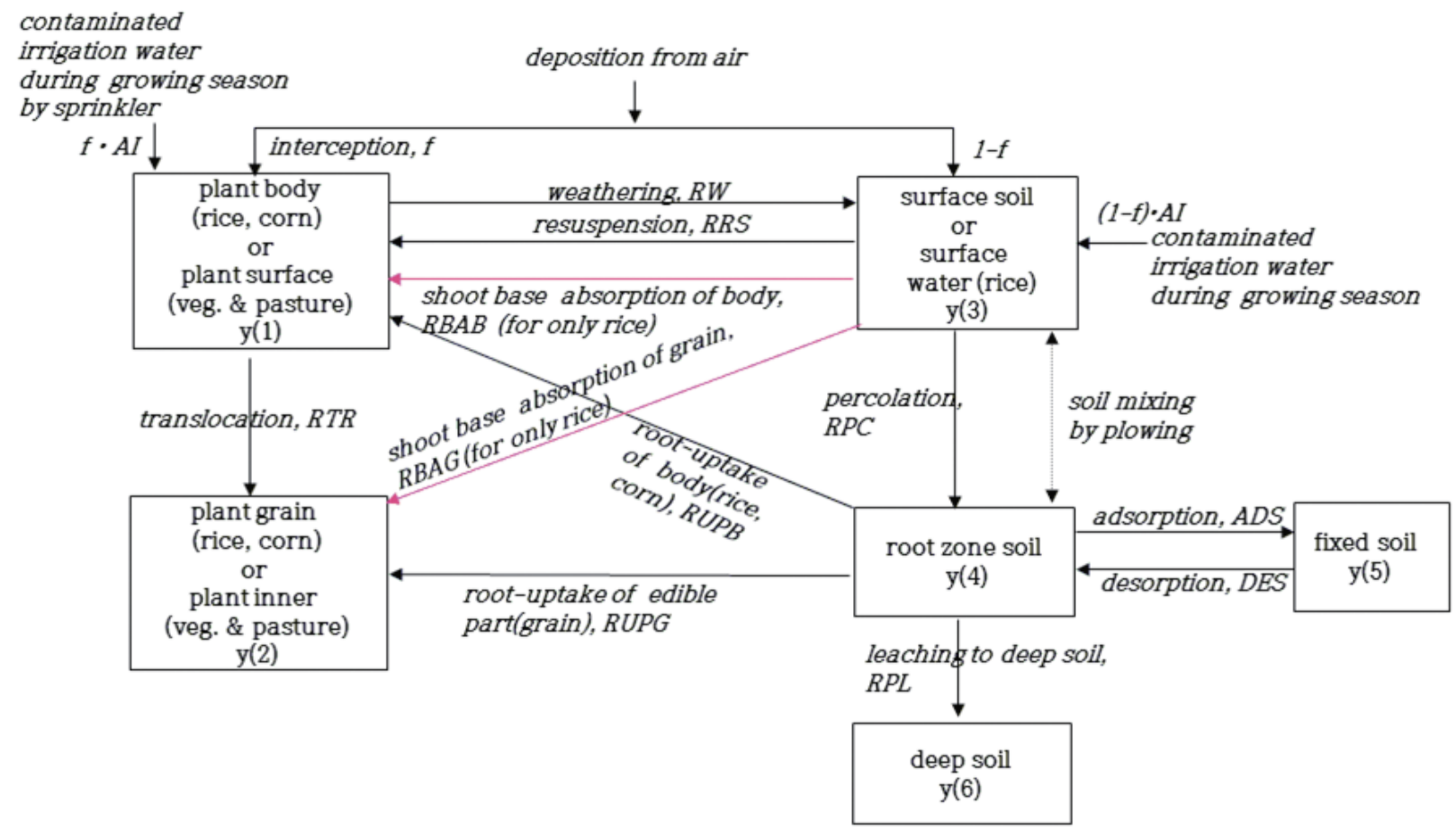

Fig. 1. Transport pathways of radionuclide in agricultural plants system [11].

water for only rice), root zone soil, fixed soil, or deep soil (sink term). The fixed soil is introduced to consider the radionuclides unavailable for root uptake by a fixation to the soil mineral, and the deep soil is a sink term of radionuclides disappearing out of the soil system. In the case of rice and corn, root uptake is assumed to occur simultaneously through both the body and grain from the root zone soil, and in the case of vegetables and pasture, root uptake is assumed to occur through only the inside of the crops from the root zone soil.

The transfer of radionuclides between compartments in Figure 1 can be described by

$$
\frac{d y_{k}}{d t}=\sum_{i=1}^{n} R_{\text {in }, i}(t)-\sum_{j=1}^{m} R_{o u t, j}(t) \pm S_{k}
$$

where $y_{k}$ is the activity concentration of compartment $\mathrm{k}$ $\left(\mathrm{Bq} \cdot \mathrm{m}^{-2}\right), R_{i n, i}$ is the inflow rate of radionuclides from compartment i to compartment $\mathrm{k}\left(\mathrm{Bq} \cdot \mathrm{m}^{-2} \cdot \mathrm{d}^{-1}\right), R_{\text {out }, j}$ is the outflow rate of radionuclides from compartment $\mathrm{k}$ to compartment $\mathrm{j}\left(\mathrm{Bq} \cdot \mathrm{m}^{-2} \cdot \mathrm{d}^{-1}\right)$, and $S_{k}$ is the source or sink term from/ to compartment $\mathrm{k}$.

\section{Animal product contamination assessment model}

The contamination of animal products occurs when livestock feed on contaminated crops and grasses. Figure 2 shows the transport pathway of radionuclide to animal prod- ucts. The animal products considered in the model are milk, beef, chicken, egg, and pork. Rice straw, corn, and pasture are considered as feed for livestock because dairy and beef cattle ingest rice-straw and wild pasture as fodder, and because corn is used as a major raw material to produce an assorted feed in a factory.

On the other hand, cattle are mostly bred indoors rather than grazing outdoors in order to meet the food taste of Koreans who likes their meat greasy. Thus, the ingestion of contaminated soil is assumed to be insignificant.

The activity concentration of animal products is determined by the product of feed intake, feed activity concentration, and feed-livestock transfer coefficient under the assumption of the equilibrium between feed and livestock.

\section{Ingestion dose assessment model}

The ingestion dose is dependent on various factors such as food intake, food type consumed, and its activity concentration. Of these factors, the activity concentration of food can be varied greatly according to the ingestion scenario of food after harvesting. The accumulated ingestion dose to time $T$ from the deposition is calculated by

$$
D_{\text {ing }}=\sum_{k=1}^{8}\left[C_{T k} \times D I_{k} \times F_{k} \times D C C_{\text {ing }}\right]
$$

where $D I_{k}$ is the daily intake of food $k\left(\mathrm{~kg} \cdot \mathrm{d}^{-1}\right), F_{k}$ is the 


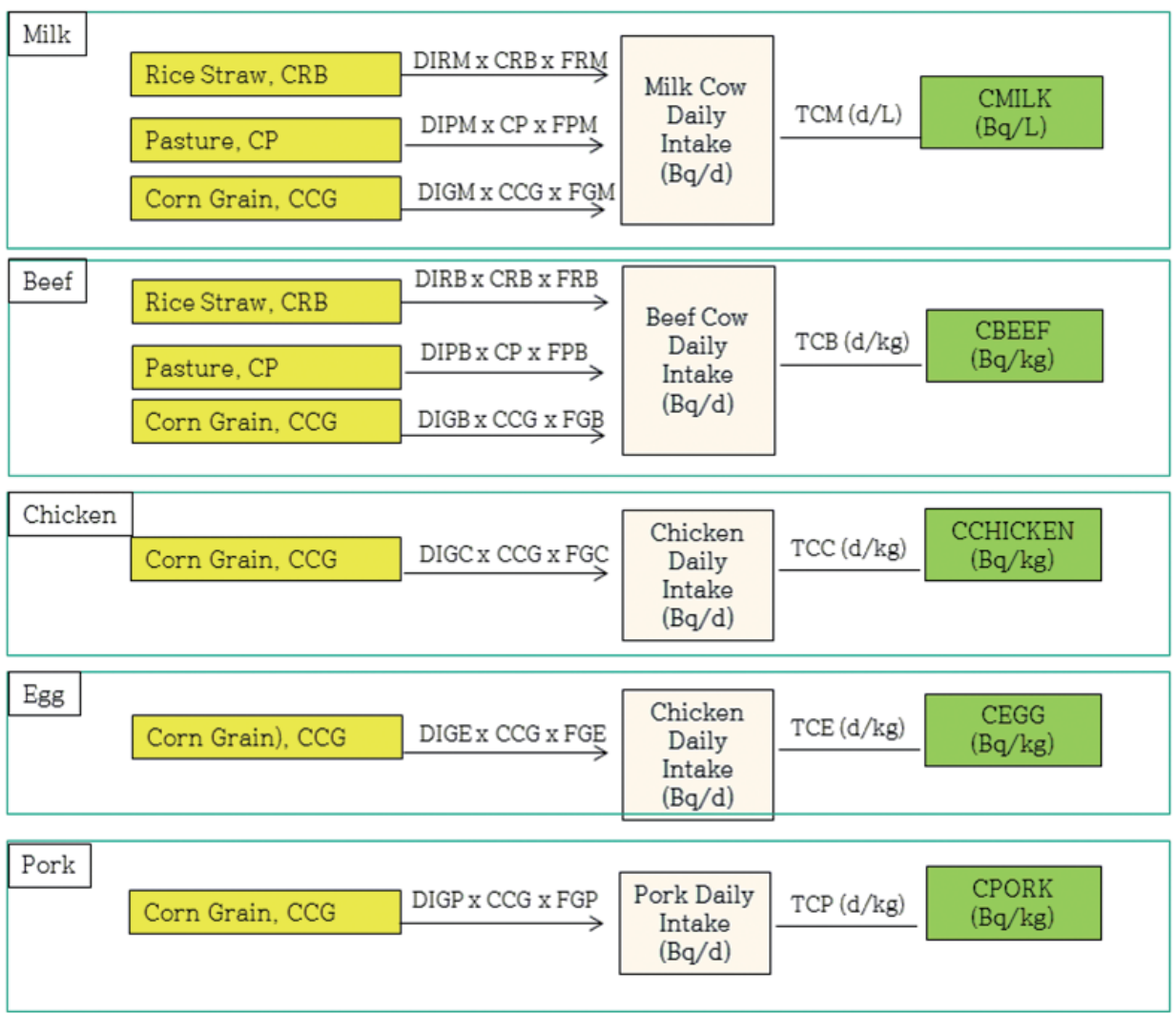

Fig. 2. Transport pathways of radionuclide to animal products [11].

fraction of contamination for food $k, D C C_{i n g}$ is the ingestion dose coefficient for a radionuclide $\left(\mathrm{Sv} \cdot \mathrm{Bq}^{-1}\right)$, and $C_{T k}$ is the time-integrated activity concentration from the deposition to time $T$ for food $k\left(\mathrm{~Bq} \cdot \mathrm{d} \cdot \mathrm{kg}^{-1}\right)$.

\section{Results and Discussion}

The performance of the model was tested through calculations of the activity concentration of agricultural plants and animal products, and ingestion dose by age groups for various deposition dates. All calculations were made for unit deposition $\left(1 \mathrm{~Bq} \cdot \mathrm{m}^{-2}\right)$ of ${ }^{137} \mathrm{Cs}$.

\section{Input data}

The values of the major input parameters used in the calculations are summarized in Table 1. More details of the input parameters are provided elsewhere [11]. The growth period of crops is shown in Figure 3. In the case of rice and corn, the growth period for the body and grain is distinguished because the emergency time of grain is different from the planting (or sowing) time. The plowing of fields, which leads to the mixing of surface soil with root zone soil, is assumed to
Table 1. Input values of major parameters used in calculations

\begin{tabular}{|c|c|c|}
\hline Parameters & Value & Reference \\
\hline Adsorption rate constant, $\mathrm{ADS}\left(\mathrm{d}^{-1}\right)$ & $1.9 \times 10^{-3}$ & [3] \\
\hline Desorption rate constant, DES $\left(\mathrm{d}^{-1}\right)$ & $2.1 \times 10^{-4}$ & [3] \\
\hline Interception constant, $\mathrm{a}\left(\mathrm{d}^{-1}\right)$ & 3.0 but 0.3 for fruit & [3] \\
\hline Percolation rate constant, $\mathrm{RPC}\left(\mathrm{d}^{-1}\right)$ & $\begin{array}{l}0.05 \text { for rice, } 0.02 \text { for } \\
\text { other plants }\end{array}$ & [10], [3] \\
\hline Translocation rate constant, RTR $\left(\mathrm{d}^{-1}\right)$ & $5.5 \times 10^{-3}$ for 7 plants & [1] \\
\hline Weathering rate constant, RTR $\left(\mathrm{d}^{-1}\right)$ & $4.95 \times 10^{-2}$ for 7 plants & [3] \\
\hline Resuspension rate constant, $R R S\left(d^{-1}\right)$ & $1.7 \times 10^{-3}$ for 7 plants & [3] \\
\hline Leaching rate constant, RPL $\left(\mathrm{d}^{-1}\right)$ & $\mathrm{RPL}=\frac{W_{i n f}}{X r s \cdot \varepsilon\left(1+\frac{\rho_{s} K_{d}}{\varepsilon}\right)}$ & [11] \\
\hline Root uptake rate, RUP (d-1) & $\mathrm{RUP}=\frac{\left(\frac{d B(t)}{d t}\right) \cdot C R}{X r s \cdot \rho_{s}}$ & [11] \\
\hline Shoot base absorption, SBA $\left(\mathrm{d}^{-1}\right)$ & $\mathrm{SBA}=\frac{B(t)}{B M A X} S B M A X$ & [11] \\
\hline Interception factor, $f$ & $\mathrm{f}=1-e^{-\alpha B(t)}$ & [11] \\
\hline $\begin{array}{l}\text { Transfer coefficient of radionuclide } \\
\text { from feed to livestock, TC }\left(\mathrm{d} \cdot \mathrm{kg}^{-1}\right)\end{array}$ & $\begin{array}{l}4.6 \times 10^{-3} \text { for milk, } 0.022 \\
\text { for beef, } 2.7 \text { for chicken, } \\
0.4 \text { for egg, } 0.2 \text { for pork }\end{array}$ & [11] \\
\hline Concentration, CR & $\begin{array}{l}\text { body: } 0.05 \text { for rice, } 0.02 \\
\text { for corn, } 0 \text { for other } \\
\text { plants } \\
\text { grain: } 0.02 \text { for all plants }\end{array}$ & [11] \\
\hline $\begin{array}{l}\text { Maximum shoot base absorption } \\
\text { rate constant of rice, SBMAX }\left(\mathrm{d}^{-1}\right)\end{array}$ & $\begin{array}{l}2.0 \times 10^{-4} \text { for rice, } 0 \text { for } \\
\text { other plant }\end{array}$ & [10] \\
\hline
\end{tabular}






Fig. 3. Growing period of crops considered in the present model.
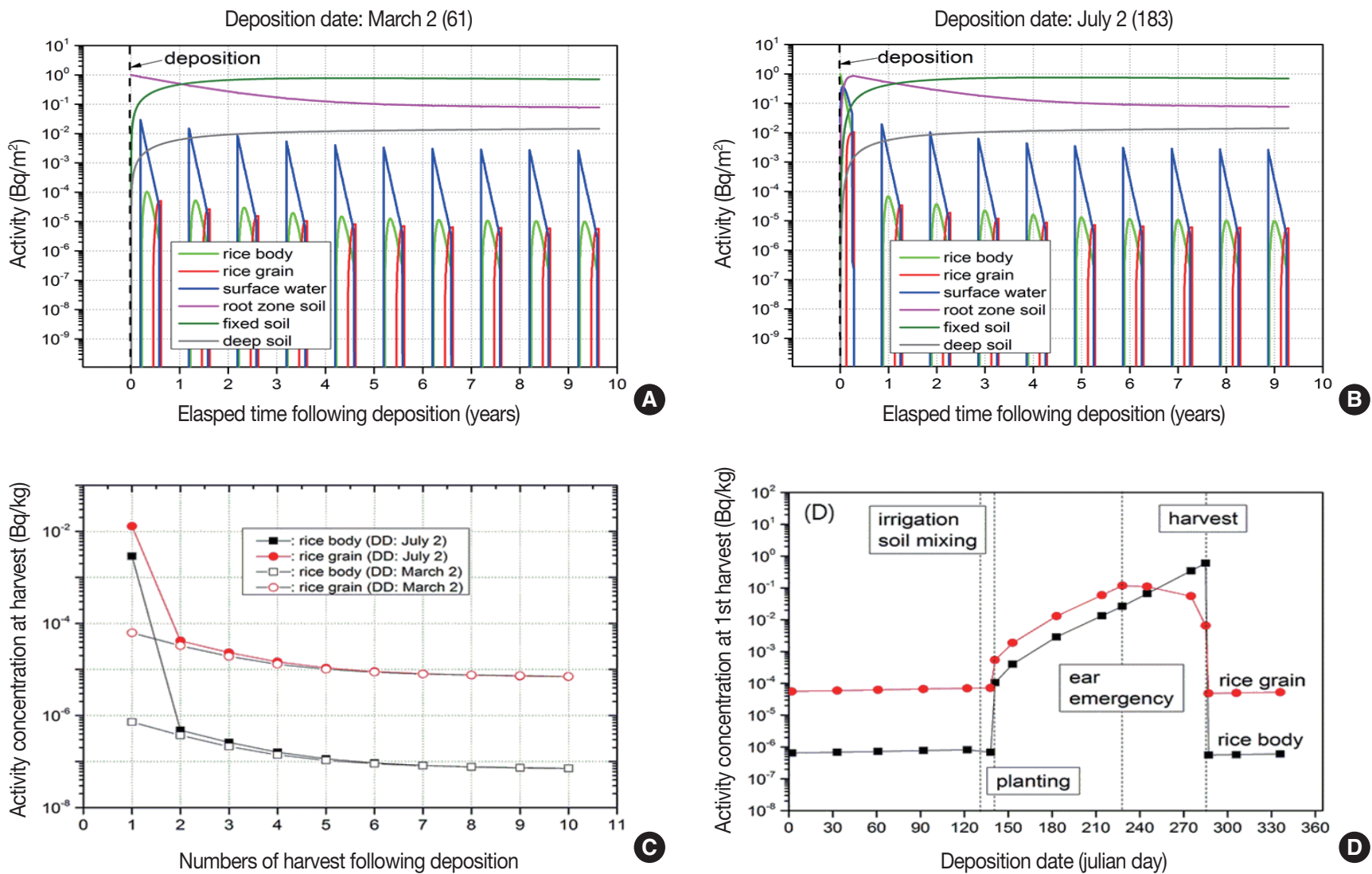

Fig. 4. Temporal ${ }^{137} \mathrm{Cs}$ activity concentration of rice for 10 years following two different deposition dates.

have occurred one day before sowing or transplanting. In the case of rice, the plowing and supply of irrigation water is assumed to have occurred ten days before transplanting. The supply of irrigation water stops on fifteen days before harvest, and thus it leads to no surface water on the paddy field until harvest. The pasture is assumed to be grown for six months from May 1 to October 10, and also it is assumed to be three harvests every two months during this period.

The daily intake of food varies widely depending on the food classification. In this study, the intake rate of food was taken from a literature [12].

At present, Korea's regulatory system for radiation protection applies the ICRP 60, in which the age groups for dose calculation are classified into six groups. Accordingly, the dose conversion coefficients for ingestion were taken from the ICRP 199 [13], which provides a database for dose conversion coefficients of the ICRP 60. 


\section{Activity concentration of rice}

Figure $4 \mathrm{~A}$ and $4 \mathrm{~B}$ show the temporal ${ }^{137} \mathrm{Cs}$ activity concentration of rice for 10 years following two different deposition dates. When a deposition occurs on March 2 (Julian day 61), before the transplanting of rice, the radionuclide is deposited onto the root zone soil because irrigation has not started yet. In this case, the transfer of the deposited radionuclides on the soil to rice starts to occur through the root uptake and short base absorption after the transplanting of rice. The activity concentration of rice body shows a peak by balancing of radionuclide between the gain due to absorption and the loss due to weathering. After an ear emergence, the activity concentration of the body is further decreased until harvest by translocation from the body to the grain, whereas the activity concentration of ear is increased continuously until harvest by the translocation process. On the other hand, when deposition occurs on July 2 (Julian day 183) in the growing season of rice, there is a direct deposition on the rice body, and consequently the activity concentration of the body and grain at first harvest after deposition becomes larger, compared with the case of the deposition before rice planting.

The initial activity concentration of the root zone soil varies depending on the time of deposition (in the case of deposition during the non-growth season of rice, radionuclides are deposited on the surface of the root zone soil, whereas in the case of deposition during the growth, a portion of radionuclides are deposited on the flooded surface water). After the initial deposition, the activity concentration of the root zone soil is decreased gradually by soil immobilization and leaching processes. The activity concentration of the flooded surface water is instantaneously increased by its mixing with the root zone soil owing to plowing before transplanting. After the plowing, the activity concentration is decreased again by the transfer of radionuclides to the root zone soil (percolation). More than $80 \%$ of the deposited ${ }^{137} \mathrm{Cs}$ remain in the fixed soil even 5 years after deposition, indicating a significant reduction of radionuclides available for root absorption. This result is consistent with the fact that most radioactive cesium was present in the soil within a $5 \mathrm{~cm}$ depth even after the recent 5 years after the Fukushima accident.

If rice is cultivated consecutively for years in contaminated paddy fields, the activity concentration of the harvested rice is decreased slowly according to the decrease in the activity concentration of root zone soil (Figure 4C). After about 3 years, the activity concentration of rice appeared to be simi- lar regardless of the deposition time because the root uptake was the main pathway of rice contamination.

The activity concentration at the first harvest after deposition varies greatly depending on when the deposition happened (Figure 4D). In the case of deposition during the growth season, the first harvest activity concentration of rice was increased markedly by the direct deposition on the surface of the rice body. The maximum activity concentration of grain was obtained when deposition occurred at the time of the ear emergence. When deposition occurred after the ear emergence, the activity concentration of the rice grain was decreased because the time allowed for translocation until harvesting became relatively shorter. On the other hand, the activity concentration of the rice body was increased as the deposition date became closer to harvest time.

\section{Effects of irrigation water contamination}

Figure 5 shows the effects of contaminated irrigation water on the ${ }^{137} \mathrm{Cs}$ activity concentration of rice for deposition on March 11 before transplanting. Under the present conditions, the effects of the contaminated irrigation water appeared to be negligible if the initial activity concentration of water was less than about $10^{-3} \mathrm{~Bq} \cdot \mathrm{m}^{-3}$, which meant that the root uptake was the dominant pathway to contaminate the rice. If the initial activity concentration of the contaminated irrigation water was above $10^{-3} \mathrm{~Bq} \cdot \mathrm{m}^{-3}$, the activity concentration rice was increased greatly. In this case, the contaminated irrigation water is the main contributor to the contamination of rice.

\section{Activity concentration of vegetables}

Figure $6 \mathrm{~A}$ and $6 \mathrm{~B}$ show the temporal ${ }^{137} \mathrm{Cs}$ activity concen-

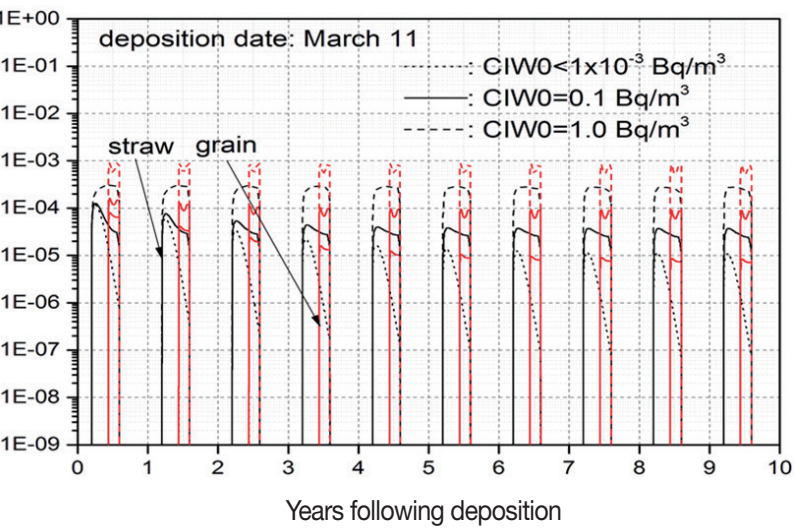

Fig. 5. Effect of contaminated irrigation water on the ${ }^{137} \mathrm{Cs}$ activity concentration of rice. 

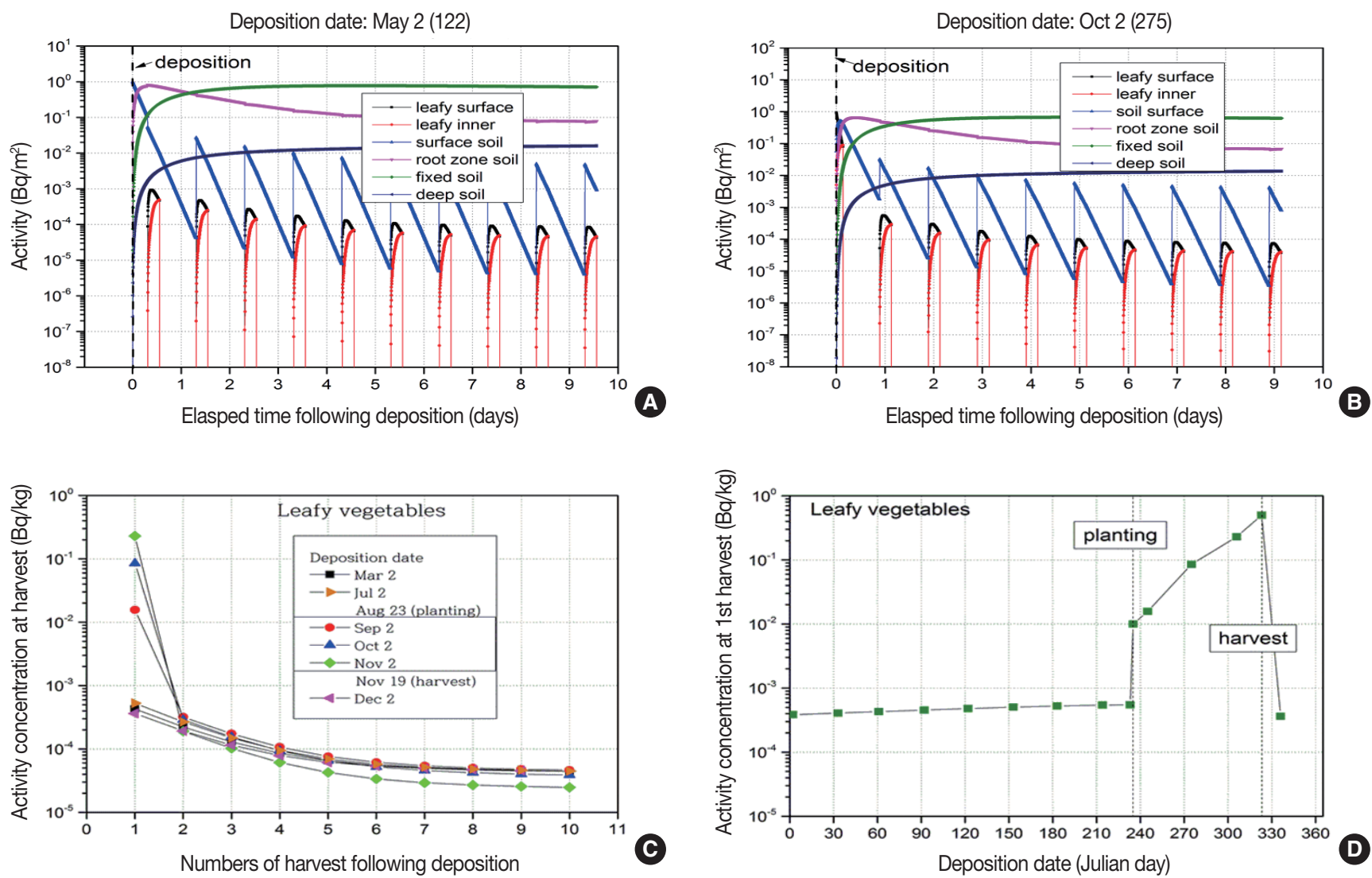

Fig. 6. Temporal ${ }^{137} \mathrm{Cs}$ activity concentration of vegetables for 10 years following deposition.

tration of vegetables (Chinese cabbage) for 10 years following two different deposition dates. The planting date of Chinese cabbage was assumed to be August 23, and the harvest was assumed to be November 19. Unlike rice, all parts of the vegetables are edible. The trend of the activity concentration for the vegetable was similar to that for rice. The activity concentration of the surface soil jumped abruptly by soil mixing, and after next year, it decreased continuously until the soil mixing the next year due to the loss of radioactivity by the percolation process. The activity concentration of vegetables showed a typical tendency to decrease continuously along with the decrease in the activity concentration of the root zone soil.

When vegetables are assumed to be grown consecutively in contaminated soil for years, the activity concentration at the first harvest appeared to be larger relatively in the case of the deposition during the growth season (Figure 6C). The activity concentration from the second year was slightly higher for the case of deposition during non-growing season than that for the case of deposition during growing season. This was ascribed by the fact that the initial activity concen- tration of surface soil was lower owing to the interception of radionuclides by plant leafs in the case of growing season deposition compared to that of the non-growing season. The lower activity concentration of surface soil leads to the lower activity concentration of root zone soil, and consequently the lower activity concentration of crop when the root uptake is the main pathway of the contamination.

The first harvest activity concentration of vegetables for the case of the deposition during the growing season increased with the deposition time closer to harvest date (Figure 6D) since the direct deposition onto the plant increased with the development of biomass. The maximum activity concentration of vegetables was obtained for the case of the deposition occurred just before harvest, when the vegetables were fully developed.

\section{Activity concentration of pasture}

Figure 7 shows the temporal ${ }^{137} \mathrm{Cs}$ activity concentration of pastures for 10 years following two different deposition dates. Pasture 3 was growing on Oct 2. Therefore, the first harvest activity concentration appeared to be in the order of pasture 

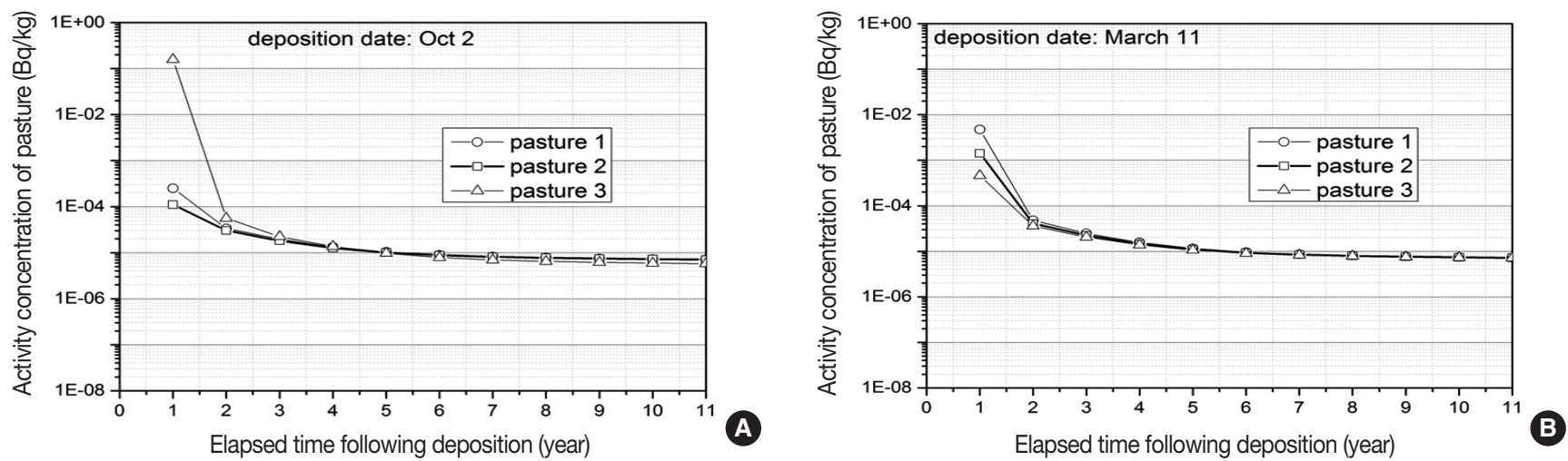

Fig. 7. Temporal ${ }^{137} \mathrm{Cs}$ activity concentration of pastures for 10 years following two different deposition dates.
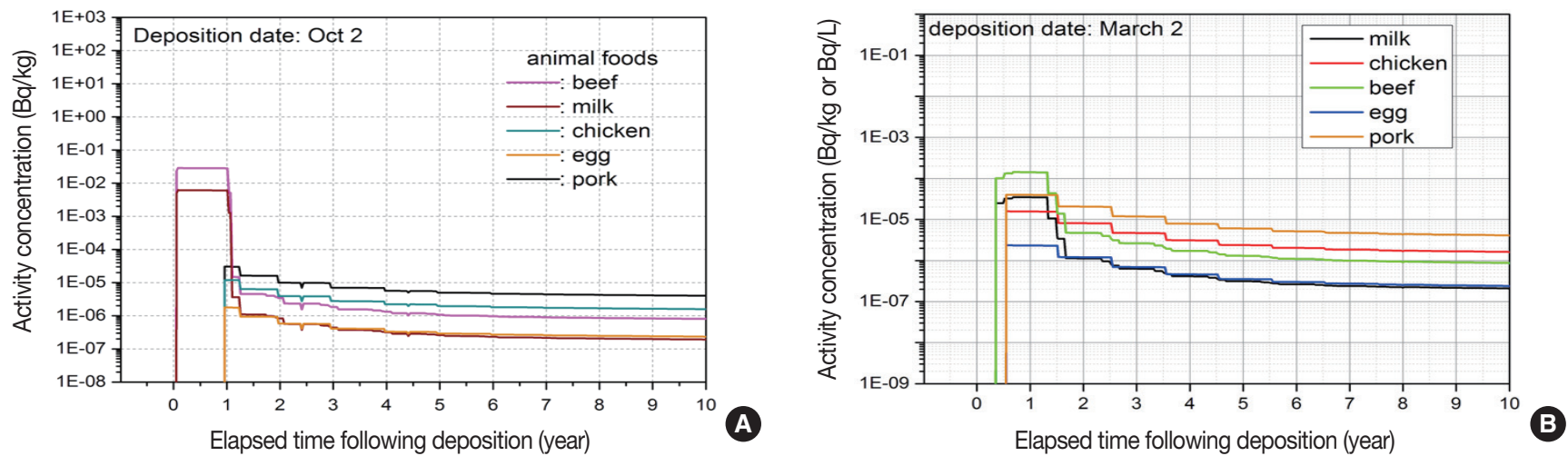

Fig. $8 .{ }^{137} \mathrm{Cs}$ activity concentration of animal products following two different deposition dates.

$3>$ pasture $1>$ pasture 2 . On the other hand, for the case of deposition on March 11 in the non-growing pasture season, there was no direct deposition onto pasture, and root uptake was the only pathway to contaminate pasture. Accordingly, the first harvest activity concentration appeared to be in the order of pasture $1>$ pasture $2>$ pasture 3 because the activity concentration of root zone soil available for root uptake was decreased with the elapsed time between deposition and harvest. The effect of the deposition date was no longer significant after the second year following deposition. The maximum activity concentration of crops was obtained for the case of the deposition on the harvest date.

\section{Activity concentration of animal products}

Figure 8 shows the temporal ${ }^{137} \mathrm{Cs}$ activity concentrations of animal products for 10 years following two different deposition dates. For the case of deposition on October 2 in the growth period of rice, corn, and pasture 3 , the first year activity concentration of these crops increased owing to the direct deposition onto the surface of the crops, and thus the activity concentrations of milk and beef also increased with the activity concentration of feedstuffs. For the case of deposition on March 2, when all crops were not grown yet, there was no direct deposition on the surface of the crop. Therefore, the activity concentrations of feedstuffs for animals were relatively smaller than that in the case of deposition during growth. As a result, the activity concentration of animal products became relatively small. For example, the maximum activity concentration of milk for the case of the deposition on October 2 was about 170 times higher than that for the case of the deposition on March 2. The calculated results also showed the activity concentration of animal products increased when the deposition approached the harvest date of crops, which would lead to a higher activity concentration of crops.

\section{Ingestion dose}

Figure 9 shows the yearly and cumulative effective ingestion dose over a 10-year period by age groups. The cumulative dose increased for the case of deposition during the 

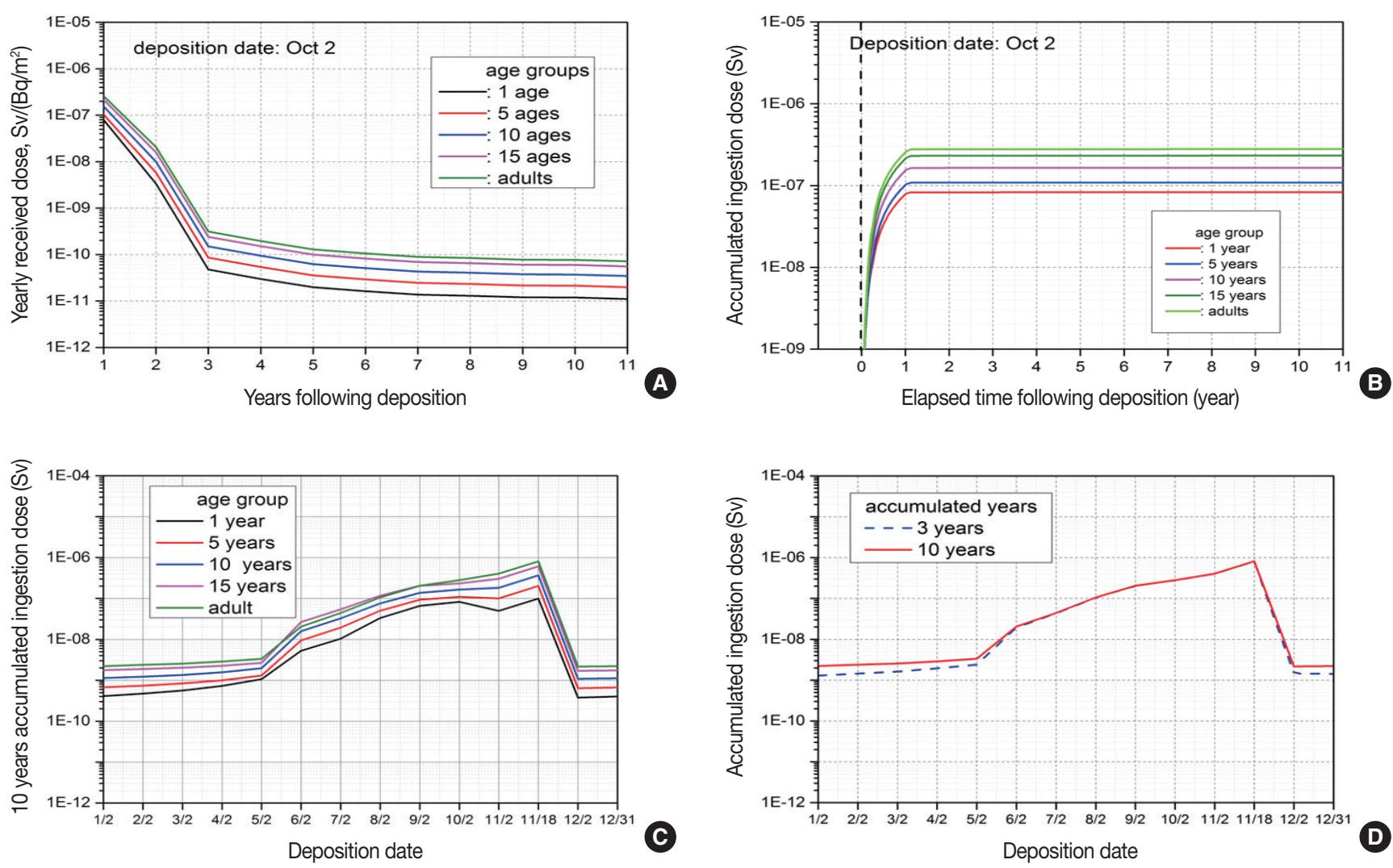

Fig. 9. The yearly and cumulative effective ingestion dose over 10 years by age groups.

growing season of the crop. The type of food contributed to the ingestion dose appears differently depending on the deposition date. In this study, the harvest of vegetables was assumed to be on November 19, and thus the maximum effective ingestion dose for adults who have the highest vegetable intake was obtained for the case of the deposition on the date. For the one-year old age group with the highest milk intake, the received effective ingestion dose reduced slightly for the case of deposition on November 2 owing to the decrease in the activity concentration of milk through the ingestion of clean pasture, whereas it increased slightly again for the deposition on November 18 because of the increased activity concentration of vegetables. It can also be seen that there was almost no difference in the cumulative effective ingestion dose for three years from that for ten years after deposition, regardless of the date of deposition. This result indicates that the effective ingestion dose received during the whole life as the consequence of a nuclear accident takes place mostly in the first three years following deposition.

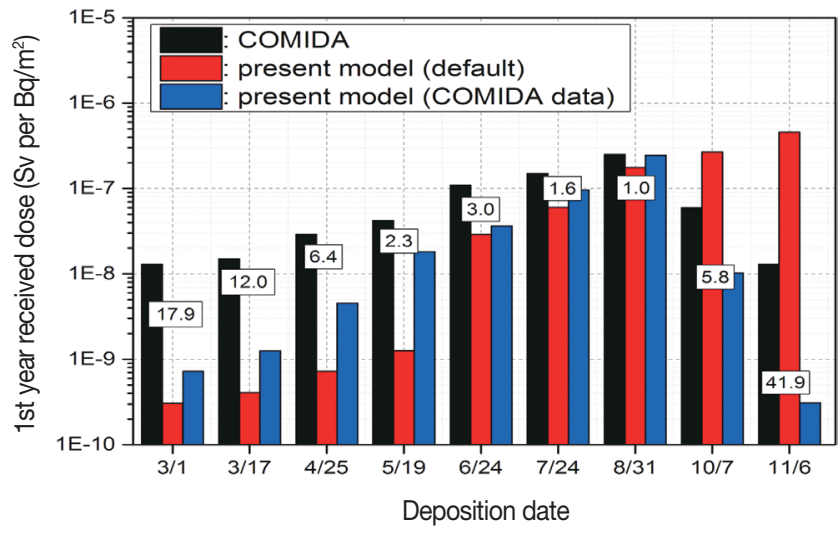

Fig. 10. Comparison of the present model with the COMIDA/ MACCS2.

\section{Comparison of the present model with COMIDA}

A model comparison was made between the COMDIA and the present model, although two models differ in the types of crops, growth characteristics, and the contamination pathways. The results for COMIDA were taken from the literature [14], whereas the calculations for the present model were made using the data applied to the calculations of 


\section{COMIDA.}

Figure 10 shows a comparison of the effective ingestion dose for adults received for one year after deposition depending on the deposition dates. For the calculations, the growth periods of the crops were assumed to be from May 1 to September 30 irrespective of the crop type. In the case of pastures, the growth periods were assumed to be from April 15 to October 15, and the pastures were harvested three times from April 15 every two months until October 15. The calculated ingestion dose profile showed a similar trend between both models but it exhibited somewhat different values depending on the deposition dates. The ratio of calculated ingestion dose for COMIDA to that for the present model was 16.7, 11.3, 5.6, 2.1, 3.1, 1.5, 1.0, 4.1, and 41.5 for the case of deposition on March 1, March 17, April 25, May 19, June 24, July 24, August 31, October 7, and November 6, respectively. The relatively large difference for the non-growing season deposition can be explained by the fact that the ingestion of pasture was the main pathway for the contamination of cattle, and COMIDA considered the soil intake and direct ingestion of pasture during grazing.

On the other hand, the results obtained using default data of the present model showed a different tendency from those of COMIDA. The highest ingestion dose for the present model was obtained for the case of deposition on November 19 , which is the harvest date of vegetables consumed a lot by adults. This result indicated that crop type, as well as the growth period, is a very significant input data to determine the deposition date resulting in the highest ingestion dose.

\section{Conclusion}

A dynamic compartment model which is composed of three sub-modules of an agricultural plant contamination assessment model, an animal product contamination assessment model, and an ingestion dose assessment model has been developed to assess the ingestion dose for public following a nuclear accident. The present model considers eight human foodstuffs (grain, vegetables, fruit, milk, beef, chicken, egg, and pork), and three livestock feedstuffs (ricestraw, pasture, and corn), which are currently being sued for the purpose of the domestic regulation. The application study showed that the present model can predict well the characteristics of the activity concentration for agricultural products and ingestion dose depending on the deposition date.
Consequently, the present model is very useful to predict the radioactivity concentration of agricultural foodstuffs and public ingestion dose as consequence of a nuclear accident. It is expected to be used effectively as a module for the ingestion dose calculation of the Korean agricultural contamination management system as well as the Level 3 PSA code, which is currently being developed.

\section{Acknowledgements}

This work was supported by the National Research Foundation of Korea (NRF) grant funded by the Korea government (NRF-2017M2A8A4015252).

\section{References}

1. Whicker FW, Kirchner TB. PATHWAY: a dynamic food chain model to predict radionuclide ingestion after fallout deposition. Health. Phys. 1987;52(6):717-737.

2. Müller H, Prőhl G. ECOSYS-87: a dynamic model for assessing radiological consequences of nuclear accidents. Health. Phys. 1993;64(3):232-252.

3. Abbott ML, Rood AS. COMIDA: a radionuclide food chain model for acute fallout deposition. Health. Phys. 1994;61(1):17-29.

4. Hwang WT, Cho G, Han MH. Development of a dynamic food chain model DYNACON and its application to Korean agricultural conditions. J. Nucl. Sci. Technol. 1998;35(6):454-461.

5. National Radiological Protection Board. A dynamic model for the transfer of radionuclides through terrestrial food chains. NRPB-R273. 1995:1-46.

6. Korea Atomic Energy Research Institute. A development of computer code for evaluating internal radiation dose through ingestion and inhalation pathways. KAER/RR998/90. 1991;290364.

7. United Nations Scientific Committee on the Effects of Atomic Radiation. UNSCEAR 2013 Report, Volume 1: Report to general assembly, scientific Annex A: Levels and effects of radiation exposure due to nuclear accident after the 2011 great east-Japan earthquake and tsunami. 2014;174-176.

8. Keum DK, Jun I, Lim KM, Choi YH. Radiation dose to human and non-human biota in the Republic of Korea resulting from the Fukushima nuclear accident. Nucl. Eng. Technol. 2013;45(1): 1-12.

9. US Department of Energy. Code manual for MACCS2: Volume 2, preprocessor codes COMIDA2, FGRDCF, IDCF2. NUREG/CR6613.Vol.2. 1998:1.1-4.4.

10. Keum DK, Lee H, Choi HJ, Kang HS, Lim KM, Choi YH, Lee CW. A dynamic model compartment model for assessing the transfer of radionuclide deposited onto flooded rice-fields. J. Environ. 
Radioact. 2004;76:349-367.

11. Korea Atomic Energy Research Institute. Model (K-PUBDOSE) to evaluate the ingestion dose following a nuclear accident. KAERI/TR-718/2018. Korea Atomic Energy Research Institute. 2018;49-100.

12. Korea Institute of Nuclear Safety. Study for an improvement of INDAC (integrated dose assessment code package). KINS/RR-
808. 2011:74-78.

13. International Commission on Radiological Protection. Compendium of dose coefficients based on ICRP Publication 60. ICRP Publication 119. Ann. ICRP 41(Suppl.). 2012:71-86.

14. Korea Atomic Energy Research Institute. A study on dose assessment system for level 3 PSA. KAERI/TR-5568/2014. 2014;61-94. 